\title{
Análise da arborização viária em dois bairros de Americana (SP) ${ }^{(1)}$
}

\author{
LUZIA FERREIRA DA SILVA ${ }^{(1,5)}$, ANDREA VOLPE-FILIK ${ }^{(2,5)}$, ANA MARIA LINER PEREIRA LIMA(2) e \\ DEMÓSTENES FERREIRA DA SILVA FILHO(3)
}

\begin{abstract}
RESUMO
A situação da arborização viária nas grandes cidades é muito precária, em decorrência da falta de planejamento adequado. Objetivou-se com o presente trabalho avaliar a situação da arborização viária em dois bairros de Americana, SP, e apresentar dados que possam servir de base para o planejamento urbano da cidade. Nos locais avaliados, foram encontradas 2.551 árvores plantadas, de 76 espécies diferentes, sendo a maioria de espécies exóticas, com maiores freqüências da Murraya paniculata (falsa-murta) - 18,42\%, Ligustrum lucidum (ligustro) - 16,50\% e Licania tomentosa (oiti) - 12,47\%, e, ainda, 63 espécies com freqüências menores que $1 \%$. Com referência à falsa-murta, verificou-se baixa porcentagem de podas drásticas, em V e L, porém a porcentagem de podas de condução e topiaria foram marcantes. A maior parte das podas foi motivada pela presença da fiação elétrica, sendo o ligustro, a canelinha e a sete-copas os que apresentaram as maiores porcentagens. O ligustro, seguido de sibipiruna e sete-copas, apresentaram raízes que afetavam estruturas urbanas, assim como maiores porcentagens de área livre insuficiente. A falsa-murta vem substituindo essas árvores, evidenciando a preferência da população e dos órgãos públicos, o que preocupa vários técnicos, por ser um arbusto que não apresenta tantos benefícios como uma árvore.
\end{abstract}

Palavras-chave: arborização urbana, inventário, arbustos.

\section{ABSTRACT \\ Condition of urban forestry in two districts of Americana/SP, Brazil}

The situation of urban forestry in great cities is very poor due to the lack of an adequate planning. We aimed at evaluating the situation of urban forestry in two districts of Americana, SP, Brazil and developing a database for a master plan of urban forestry. It was found a total of 2,551 trees belonging to 76 species, being the majority exotic species, with the highest frequencies of Murraya paniculata (Rutaceae: jasmine) with $18.42 \%$, Ligustrum lucidum (Oleaceae: privet) with $16.50 \%$ and Licania tomentosa (Crhysobalanaceae: oiti) with $12,47 \%$, and still 63 species with frequencies not higher than $1 \%$. Drastic pruning in "V" or "L" at the jasmine trees was not frequent; however, the rates of conducting pruning and shaping pruning were remarkable. The majority of prunings were motivated by the presence of electric wires, and privet, canelinha and sete-copas showed the highest pruning rates. Privet, followed by Caesalpinia pluviosa D.C.and Terminalia catappa L. showed roots affecting urban structures, as well as the highest rates of free scarce zone. Jasmine is being substituted by these species, emphasizing popular and governmental preferences, which is concerning many experts because shrubs do not offer the same benefits as trees.

Key-words: urban forestry, inventory, shrubs.

\section{INTRODUÇÃO}

Com o crescimento exacerbado das cidades, a arborização urbana ficou prejudicada, principalmente em relação ao planejamento, manejo e plantio de árvores, além de ser colocada em segundo plano pelos órgãos competentes. A população precisa perceber a relação dos vários benefícios associados à arborização urbana, como também, as ligações desta com a qualidade de vida.

As cidades necessitam do crescimento e Americana é uma delas, expandindo sua área-limite com bairros bem populosos como os escolhidos para esta pesquisa.

Anteriormente ao presente estudo, não se verificou nenhum diagnóstico das árvores existentes nesses bairros, tampouco um planejamento adequado que vise ao aumento de espécies.

Para que os benefícios da arborização urbana sejam eficientes, é necessário observar a diversidade de espécies, idade e localização, em relação às pessoas e outros elementos da paisagem (DWYER et al., 1992). Ainda, é preciso considerar a qualidade do ar, o clima, a economia de energia (pelo uso racional de ar-condicionado de ambientes), o

(1) Parte da Dissertação de Mestrado em Agronomia apresentada pela primeira autora à Escola Superior de Agricultura "Luiz de Queiroz", Universidade de São Paulo (ESALQ/USP). Recebido para publicação em 04/07/2007 e aceito em 30/072008.

$\left({ }^{2}\right)$ Doutorandas do Departamento de Produção Vegetal - ESALQ/USP. Av. Pádua dias nº 11, 13418-900 Piracicaba (SP). e-mail: luziafsilva2007@ig.com.br

(3) Professora Doutora do Departamento de Produção Vegetal - ESALQ/USP

$\left({ }^{4}\right)$ Professor Doutor do Departamento de Ciências Florestais - ESALQ/USP

$\left({ }^{5}\right)$ Bolsista CNPq. 
sistema hidrológico (pela redução de enxurradas e inundações), o armazenamento de carbono, a redução do barulho e dos ventos, a questão estética e o valor econômico do imóvel (GREY e DENEKE, 1978; DWYER et al., 1992; McPHERSON e SIMPSON, 2002).

Os benefícios somente serão percebidos quando houver um planejamento, a longo prazo, que estabeleça metas, na escolha de espécies, de plantio e manejo para arborização viária. Para tanto, é importante que os planejadores tenham acesso a algumas informações básicas, principalmente, em relação ao número de espécies existentes no local, seu porte e manejo e, ainda, quanto à verificação de lugares com possibilidades de plantio. Os inventários podem fornecer esses dados, permitindo desenvolver planos preliminares e orçamentos para plantio, podas e remoção de árvores (MILLER, 1997).

Desse modo, este trabalho teve como objetivos avaliar a situação da arborização viária, por meio de inventário, em dois bairros de Americana/SP, e levantar dados que sirvam de subsídios para o planejamento de sua arborização urbana.

\section{MATERIAL E MÉTODOS}

\subsection{Descrição do local}

A pesquisa foi desenvolvida no período de julho e agosto de 2004, no município de Americana, região metropolitana de Campinas, Estado de São Paulo, localizado a $22^{\circ} 44^{\prime} 21$ " de latitude sul, $47^{\circ} 19^{\prime} 53^{\prime \prime}$ de longitude oeste, com clima do tipo Cwa (inverno seco e verão quente), precipitação média anual de $1.280 \mathrm{~mm}$; é tropical mesotérmico de inverno seco (meses de abril a setembro), com temperatura mínima de $18^{\circ} \mathrm{C}$, estação chuvosa (meses de outubro a março) e temperatura máxima de $25^{\circ} \mathrm{C}$. Os solos predominantes são Latossolo Vermelho-Amarelo e Argissolo Vermelho-Amarelo (classificação atual); a topografia é suave com colinas médias e pequenas (MEDEIROS, 2003).

A população de Americana é de 97.345 habitantes e a taxa de urbanização, de 99,8\% (IBGE, 2005). A cidade possui intensa verticalização, com ocupação de áreas de preservação e poluição das águas em virtude das instalações de indústrias e de outras fontes poluidoras (NASCIMENTO, 2003).

\subsection{Obtenção dos dados}

Os dados foram coletados por meio do inventário total das árvores existentes nos bairros Antônio Zanaga I e II, com avaliações quantitativas e qualitativas, computados no sistema Microsoft Access. O inventário envolveu todos os indivíduos, sem utilizar critérios de censura para aqueles muito jovens. Nos lugares que apresentaram falhas (covas vazias ou cimentadas) ou tocos, verificou-se o potencial para o plantio.

Os bairros são compostos de conjunto habitacionais para pessoas de baixa renda; as casas são do tipo popular, pequena área de construção com arquitetura similar.

As informações foram coletadas e registradas em uma tabela de campo (tabela 1), considerando três aspectos importantes: localização, infra-estrutura e dados sobre a árvore; o processo de análise levou em conta as condições externas que prejudicam ou não seu desenvolvimento.

Nos itens avaliados sobre localização foram considerados o nome do bairro e da rua, largura da rua (m) e da calçada $(\mathrm{m})$; presença de fiação elétrica (secundária, primária e telefônica) e número da casa; área livre (espaço entre o colo da planta e o pavimento): 1 - ausente (totalmente pavimentado); 2 - suficiente (com mais de 10 cm de terra ao redor do tronco); 3 -insuficiente (com menos de $10 \mathrm{~cm}$ de terra ao redor do tronco). Para a infra-estrutura, verificou-se o tipo de piso: 1 - cimento; 2 - mosaico português; 3 - calçada verde (quando tiver $50 \%$ ou mais de gramas) e a adequação ao local: 1 - adequada (a árvore tem espaço para se desenvolver); 2 - inadequada (a árvore não tem espaço para se desenvolver).

Nos dados da árvore, levantou-se o nome comum das espécies, árvore morta e/ou toco, covas vazias; possibilidade de plantio: 1, 2, 3 ou 4 árvores; circunferência à altura do peito - CAP (este item foi avaliado apenas em árvores, excluindo-se os arbustos, pois a grande maioria apresentava significativo perfilhamento, e depois convertido em diâmetro à altura do peito - DAP); altura das árvores: 1 -menor que 1,30 m,2-entre 1,30 m e linha de telefonia $(6,0 \mathrm{~m}), 3$ - da linha da telefonia até a rede secundária $(8,0 \mathrm{~m}), 4$ - entre a rede secundária e primária $(12,0 \mathrm{~m}), 5$ - acima da rede primária; diâmetro da copa (medido em metros, com fita métrica e com base na rede elétrica da Companhia Paulista de Força e Luz). Além dos tipos de poda encontrados ( 1 - sem poda, 2 - de condução, 3 - topiaria, 4-forma de V, 5 - forma de L, 6-drástica ou mutiladora), foram avaliados os seus prováveis determinantes ( $\mathrm{a}$ - iluminação, b - banca de jornal, c ponto de ônibus, $\mathrm{d}$ - entrada de garagem, $\mathrm{e}$ - fiação elétrica, $\mathrm{f}$ - entupimento de calhas, $\mathrm{g}$ - sem causa aparente).

Levou-se em consideração, ainda, o sistema radicular: 1 - não aparente, 2 - com início de saliência na calçada, 3 - afetando estruturas (calçadas, guias e muros); tronco: 1 -sem injúrias mecânicas, 2 -oco, com cavidades, 3 -com fendas longitudinais, 4 - anelamento completo, 5 - inclinado; problemas: 1 - pragas, 2 - doença.

\section{RESULTADOS E DISCUSSÃO}

\subsection{Distribuição das espécies}

Verificaram-se 2.551 indivíduos (tabela 2) e 76 espécies, contabilizados em 94 ruas, sendo as espécies distribuídas de forma heterogênea e apresentando, na maioria, apenas um indivíduo por residência.

$\mathrm{Na}$ tabela 2, a freqüência das espécies Murraya paniculata, Ligustrum lucidum e Licania tomentosa é $18,42 \%, 16,50 \%$ e $12,47 \%$, respectivamente, ultrapassando o máximo de $10 \%$ do total do número de árvores, recomendado por GREY e DENEKE (1978) e SANTAMOUR JÚNIOR (1990), podendo ocorrer um declínio causado por pragas e doenças, comprometendo a longevidade das plantas. Por outro lado, existem 63 espécies com freqüências menores que $1 \%$, que acabam por gerar uma confusão visual pouco atrativa (SANTOS, 1994), além de depreciar a estética e a escala em certos lugares. Para REIS et al. (2003), o espaço urbano requer o maior número de espécies possível, a fím de valorizar a biodiversidade, enquanto MILANO e DALCIN (2000), 
consideram adequado entre 10 e 20 espécies.

O uso de apenas uma espécie arbórea nos plantios recentes pode prejudicar a diversidade da arborização no futuro, pois, com o aumento da freqüência dessa espécie, haverá uma tendência perigosa de perda da diversidade e riscos para a arborização, principalmente, quando esses plantios jovens sucederem as árvores mais velhas ou com problemas (SILVA FILHO et al., 2002).

Nos bairros analisados, constataram-se $58,60 \%$ de espécies exóticas e $41,40 \%$ de espécies nativas (tabela 3); a porcentagem de exóticas supera as nativas, fato também evidenciado no trabalho de BORTOLETO (2004), na Estância Turística de Águas de São Pedro/SP. O costume de plantar espécies exóticas no meio urbano revela a falta de conhecimento sobre sua origem e estimula a imitação de uma cidade para outra. Poucos estudos, em relação à flora brasileira, podem ter acarretado o plantio de espécies exóticas, aumentando sua porcentagem nas cidades brasileiras, conforme observado por LORENZI (1992).

A introdução de espécies exóticas na arborização urbana é questionada por vários técnicos. Para REIS et al. (2003), faz-se necessário um histórico com análise de suas potencialidades e o cuidado para que essas espécies não se tornem contaminadoras dos ecossistemas naturais.

De acordo com SANTOS (2000), as espécies nativas devem ser consideradas, especialmente, pelo seu valor sóciocultural e conservação genética. Outros autores, como PORTO ALEGRE (2000), ressaltaram que as espécies nativas exigem menos manutenção do que as exóticas no meio urbano, e é coerente obter a diversidade almejada com o uso de espécies nativas regionais.

\subsection{Porte e diâmetro à altura do peito (DAP)}

$\mathrm{Na}$ figura 1, observam-se as classes de altura encontradas, sendo 1.493 dos indivíduos com alturas entre 1,30 e $6,00 \mathrm{~m} ; 363$ de 8,00 a $12,00 \mathrm{~m} ; 312$ menores que $1,30 \mathrm{~m} ; 181$ maiores que $12,00 \mathrm{~m}$ e 175 de 6,00 a $8,00 \mathrm{~m}$. O número de indivíduos com alturas maiores que $6,00 \mathrm{~m}$ foi pequeno, fato que preocupa, pois acima desta altura é que se podem verificar os benefícios fornecidos pelas árvores à população e ao meio ambiente, de acordo com GREY e DENEKE (1978), DWYER et al. (1992) e McPHERSON e SIMPSON (2002).

A classe de altura de 1,30 a $6,00 \mathrm{~m}$ foi muito representativa na avaliação efetuada; as espécies que mais se destacaram foram a falsa-murta $(24,58 \%)$, o ligustro $(16,14 \%)$ e o oiti $(15,54 \%)$ (tabela 4$)$. Verifica-se que o ligustro também foi representativo nas alturas de 8,00 a $12,00 \mathrm{~m}$, isto é, entre a fiação secundária e primária, com $27,27 \%$. Aliadas a esta classe de altura, apareceram a sibipiruna $(23,14 \%)$ e a sete-copas $(17,36 \%)$. A falsa-murta também apresentou grande destaque nas alturas menores que $1,30 \mathrm{~m}$, representando $30,77 \%$ do plantio, juntamente com o oiti, com $20,83 \%$. Portanto, a falsa-murta vem sendo bem representada, tanto nas alturas menores que $1,30 \mathrm{~m}$, como na de 1,30 a 6,00 m, evidenciando os plantios recentes ocorridos nos bairros. Observou-se que a falsa-murta vem substituindo as sibipirunas e sete copas. A substituição de árvores de grande porte por arbustos denota prática comum nas cidades brasileiras, o que, com certeza, levará a um comprometimento, em curto prazo, pois há o risco de não serem encontradas mais árvores plantadas nas calçadas.

A falsa-murta, juntamente com resedá-anão, hibisco e espirradeira, têm porte reduzido e apresentam restritas possibilidades de contribuição para melhoria climática e ambiental das cidades (MILANO e DALCIN, 2000). Embora sejam sugeridas como "apropriadas" para uso sob fiação elétrica, elas trazem poucos benefícios em relação às árvores de grande porte, na providência de sombra, absorção da poluição do ar e interceptação da água da chuva (McPHERSON et al. 1999).

De acordo com NOWAK e CRANE (2002), a opção pelas árvores maiores é um fator importante, porque elas atuam como um depósito de gás carbônico, pela fixação de carbono, durante a fotossíntese e podem reduzir, potencialmente, o acúmulo de carbono atmosférico.

Ao analisar a figura 2 nota-se maior número de árvores com diâmetro à altura do peito (DAP) entre $0,25 \mathrm{e}$ $0,30 \mathrm{~m}$, indicando que o plantio de árvores jovens nos bairros está bem abaixo do recomendado por FORMAN e GODRON (1986). Esses autores sugeriram um gráfico sobre a curva de crescimento das espécies, observando a porcentagem de indivíduos sobreviventes em relação à porcentagem dos diversos períodos de crescimento das espécies arbóreas (DAP). Esse gráfico mostra a necessidade de alto percentual de indivíduos jovens, no período inicial, devido à alta mortalidade que ocorre na fase adulta.

Se não houver um número maior de indivíduos jovens plantados, a arborização urbana, no futuro, pode ser comprometida, pois haverá momento em que a população de árvores não será a mesma - quando ocorrer morte destes indivíduos, de 0,25 e 0,30 m de DAP, não haverá árvores jovens para substituí-los, o que pode influenciar a estabilidade da população e a necessidade de manejo.

No trabalho de McPHERSON e SIMPSON (2002), os autores observaram a população de árvores em duas cidades dos Estados Unidos e verificaram que, na cidade de Modesto, havia 30\% de árvores jovens (DAP entre 15 a $35 \mathrm{~cm}$ ) e $20 \%$ de árvores mais velhas (DAP ente 55 a 75 $\mathrm{cm}$ ), enquanto, na cidade de Santa Mônica, 35\% a 42\% de árvores jovens (DAP entre $15 \mathrm{a} 35 \mathrm{~cm}$ ) e 10\% de árvores mais velhas (DAP entre 55 a $75 \mathrm{~cm}$ ). Eles usaram a curva "ideal" para verificar a estabilidade da população, proposta por RICHARDS (1983), e constataram, na cidade de Modesto, uma população de árvores bem diferente da proposta "ideal" de distribuição, ao passo que, na cidade de Santa Mônica, igualou-se à distribuição "ideal” em quase todos os pontos. Portanto, existem muitos indivíduos jovens em Santa Mônica para substituir os indivíduos velhos, no futuro.

\subsection{Tipos de podas - o mito fiação elétrica e árvores grandes}

A maioria dos indivíduos - 52,60\% - sofreu podas (tabela 5), o que demonstra um alto custo de manutenção para a Prefeitura, para a Companhia Paulista de Força e Luz - CPFL e também para os moradores, que fazem esta prática comumente, ainda que a lei proíba.

A poda drástica correspondeu a $39,51 \%$ das podas efetuadas, o que faz presumir que tanto os moradores como a Prefeitura realizam-nas, em flagrante desrespeito à legislação municipal e federal. 
Não há dúvida de que a poda é uma prática de manejo da arborização urbana de grande significado, porém, os meios como é efetivada gera muito conflito (MILANO e DALCIN, 2000).

Segundo SEITZ (1990), para a correta utilização da poda, é necessário reconhecer seus tipos básicos e utilizar a mais recomendada para cada caso, tal como a poda de formação ou educação, manutenção ou limpeza e, quando as anteriores forem incorretas, a de segurança.

Dentre os 1.008 indivíduos podados drasticamente (tabela 6), 60,42\% foram por causa da fiação elétrica; $31,52 \%$ sem motivo aparente; $3,47 \%$ por entupimento de calhas; $0,50 \%$ por presença de garagem, e $0,10 \%$ em favor da iluminação.

Os conflitos entre árvores e redes elétricas aéreas são vistos de maneira crítica, pois há coincidência da altura das árvores médias e grandes com as redes elétricas aéreas, o que gera o mito de não plantá-las sob a fiação. Segundo MILANO e DALCIN (2000), árvores de grande porte podem ser utilizadas sob redes, com restritos problemas e baixas demandas de podas. Eles sugerem que o plantio de árvores de grande porte pode ocorrer quando a largura das calçadas e ruas e o afastamento predial das construções permitem o livre desenvolvimento, sendo conduzidas por podas, de forma que suas copas sejam liberadas, após ultrapassarem a rede aérea.

A alta porcentagem de podas drásticas, sem motivo aparente $(31,52 \%)$ - tabela 6 , demonstra uma tendência errada de se fazer esta prática sem necessidade, comprometendo a forma peculiar da árvore e resultando em sua morte, após alguns anos, além de reduzir muitos benefícios que a árvore proporciona, por meio do processo folha-atmosfera (fotossíntese, transpiração e interceptação da água da chuva).

O mito de plantar arbustos ou árvores de pequeno porte, para mitigar os problemas com fiação elétrica, é bem comum nas cidades, e os bairros analisados no trabalho não foram diferentes, pois houve predominância da falsa-murta.

Não foram encontrados muitos indivíduos de falsamurta com podas drásticas, em $\mathrm{V} \mathrm{e} \mathrm{L}$, porém, a porcentagem de podas de condução e topiaria foram evidentes (tabela 7). Esta espécie precisa de poda de condução no viveiro e, após o plantio, com maior freqüência, para não se transformar em moita nas calçadas, motivo de grande transtorno para os pedestres, além de manutenção onerosa para a Prefeitura e os moradores. A sibipiruna apresenta maior porcentagem de podas em $\mathrm{V}$ e em L, em função da fiação elétrica. Ressalta-se no trabalho de VELASCO (2003) que as sibipirunas de Piracicaba estavam mais doentes do que as de Maringá, em decorrência de podas mal feitas, e não, da espécie, que apresenta potencial para arborização viária.

As espécies que sofreram poda drástica, em virtude da fiação elétrica, foram ligustro, canelinha e sete-copas, conforme se verifica na tabela 8 . Após freqüentes podas, o ligustro apresenta problemas no seu tronco, pois surgem grandes ocos, que comprometem a estabilidade da árvore (SANTOS, 1994). Quanto à canelinha, constatou-se a presença de galhas, ocasionado, provavelmente, pela disseminação da poda.

A poda drástica da sibipiruna vem diminuindo, devido à proposta de manejo que as companhias de energia elétrica adotaram, optando pela poda em $\mathrm{V}$ e L, de efeito igual ou pior. Com relação ao ligustro, à canelinha e à setecopas observaram-se em campo brotações epicórmicas. Para MILANO e DALCIN (2000), tais brotações manifestamse como forma de compensação na árvore, proporcionalmente à intensidade de poda, desencadeando a quebra da dormência das gemas epicórmicas (brotos ladrões), o que provoca uma rápida brotação e descaracterização do modelo arquitetônico original da espécie.

As lesões causadas por poda devem ser reduzidas ao máximo, pois funcionarão como entradas potenciais para microorganismos apodrecedores - insetos ou doenças - além de exigirem tratamento extensivo e oneroso, muitas vezes infrutífero, em árvores isoladas, espalhadas pela cidade.

\subsection{Sistema radicular e área livre no canteiro}

O ligustro apresentou maior porcentagem de raízes que afetaram a estrutura da calçada $(28 \%)$ e, também, de área livre do canteiro insuficiente $(27,35 \%)$ (tabela 9$)$. A área livre do canteiro e o tipo de espécie são itens a serem analisados nos plantios, levando em consideração a estrutura da árvore, quando adulta, além de outros fatores relevantes. Estudos já foram feitos sobre a correlação inversa entre o tamanho da área livre de pavimentação, deixada na base das árvores, e os danos às calçadas (MILANO, 1996). A distância deixada em volta do tronco é bem reduzida, e as árvores com raízes mais superficiais sofrem com esta limitação.

De acordo com DODGE e GEIGER (2001), observou-se, nos registros de manejo, que os fatores mais importantes associados a danos em estruturas são os espaços restritos de plantio, espécies incorretas, solos rasos e compactados e lugares inadequados. Ainda, para FRANCIS et al. (1996), além destes cuidados no manejo, deve-se levar em conta a fase adulta da árvore e a taxa de crescimento de cada espécie.

\subsection{Tronco, problemas com doenças e adequação ao local}

A maioria das espécies encontradas apresentou fendas longitudinais nos troncos, correspondendo a $86,58 \%$ das espécies analisadas (Tabela 10). As fendas longitudinais podem ser focos de entrada de patógenos na planta. Apesar desse fato, não foram constatados muitos indivíduos doentes, embora a presença de pragas tenha sido alta (Tabela 11). $\mathrm{O}$ cupim foi a praga mais comum encontrada nos indivíduos, e o fungo Drepanoconis larvarum, um tipo de galha, foi muito constatado nas canelinhas, o que é comum nessas espécies.

\section{CONCLUSÃO}

De acordo com as observações nos dois bairros estudados, é necessário rever o manejo dado às árvores viárias e propor um planejamento que contemple os problemas encontrados. A população deve ser orientada por meio da educação ambiental sobre os tipos de podas e o que elas podem causar às árvores, para que essa prática não seja feita por ela própria e, sim, por órgão público competente. 


\section{AGRADECIMENTOS}

Os autores agradecem ao Conselho Nacional de Desenvolvimento Científico e Tecnológico - CNPq, que contribuiu com o apoio financeiro para a realização deste trabalho.

\section{REFERÊNCIAS BIBLIOGRÁFICAS}

BORTOLETO, S. Inventário quali-quantitativo da arborização viária da Estância de Águas e São Pedro SP. 2004. 85 f. Dissertação (Mestrado em Fitotecnia) Escola Superior de Agricultura "Luiz de Queiroz", Universidade de São Paulo, Piracicaba, 2004.

DODGE, L.; GEIGER, J. Tree roots and sidewalk damage. Western Arborist, Davis, v.29, n.3, p.28-29, 2001.

DWYER, F. et al. Assessing the benefits and costs of the urban forest. Journal of Arboriculture, Illinois, v. 18, n.5, p.227-234, 1992.

FORMAN, R.T.T.; GODRON, M. Landscape ecology. New York: John Wiley, 1986. 620p.

FRANCIS, J.K.; PARRESOL, B.R.; PATIÑO, J.M. Probability of damage to sidewalks and curbs by street trees in the tropics. Journal of Arboriculture, Illinois, v.22, n.4, p.193-197, 1996.

GREY, G.W.; DENEKE, F.J. Urban forestry. New York: John Wiley, 1978. 279 p.

INSTITUTO BRASILEIRO DE GEOGRAFIA E ESTATÍSTICA-IBGE. Disponível em: http:// www.ibge.hpg.gov.br, Acesso em: 18 set. 2005.

L o r e n z I, h . Árvores brasileiras: manual de identificação e cultivo de plantas arbóreas nativas do Brasil. Nova Odessa: Editora Plantarum, 1992. v.1. 352p.

McPHERSON, E.G.; SIMPSON, J.R. A comparison of municipal forest benefits and costs in Modesto and Santa Monica, California, USA. Urban Forestry \& Urban Green. Davis, n.1, p.61-74, 2002.

et al. Tree guidelines for San Joaquimn Valley communites. Sacramento: Government Commission Sacramento, C. A. 1999.68 p.

MEDEIROS, A.C. Análise ambiental do processo de urbanização em Americana SP: diretrizes para elaboração da gestão ambiental, através de técnica de geoprocessamento. 2003. 200f. Dissertação (Mestrado em Gestão Ambiental) - Universidade Metodista de Piracicaba, Piracicaba, 2003.

MILANO, M.S. Arborização urbana no Brasil: mitos e realidade. In: CONGRESSO BRASILEIRO DE ARBORIZAÇÃO URBANA, 3., 1996, Salvador. Anais.... Salvador: COELBA, 1996. p.1-6.
; DALCIN, E.C. Arborização de vias públicas. Rio de Janeiro: Light, 2000. 226 p.

MILLER, R.W. Urban forestry: planning and managing urban geenspaces. 2.ed. New Jersey: Prentice Hall, 1997. 404p.

NASCIMENTO, C.B. Análise da vulnerabilidade ambiental na implantação de áreas industriais no território de Americana - SP, utilizando geoprocessamento. 2003. 215f. Dissertação (Mestrado em Gestão Ambiental) - Universidade Metodista de Piracicaba, Piracicaba, 2003.

NOWAK, D.J.; CRANE, D.E. Carbon storage e sequestration by urban trees in the USA. Environmental Pollution, London, v.116, p.381-389, 2002.

PORTO ALEGRE. Secretaria Municipal do Meio Ambiente. Plano diretor da arborização de vias públicas. Porto Alegre: Prefeitura, 2000. 204p.

REIS, A. et al. Critérios para a seleção de espécies na arborização urbana ecológica. Sellowia, Itajaí, v.53, n. 55, p.51-67, 2003.

RICHARDS, N.A . Diversity and stability in a street tree population. Urban Ecology, Amsterdam, v.7, p.159-171, 1982/83.

SANTAMOUR JÚNIOR, F.S. Trees for urban planting: diversity uniformity, and common sense. In: METRIA CONFERENCE, 7., 1990, Lisle. Proceedings... Lisle, 1990. p.57-66.

SANTOS, E. Caracterização dendrológica e estética de $\mathbf{1 8}$ espécies arbóreas com potencial de uso em paisagismo e arborização urbana. 1994, 146f. Dissertação (Mestrado em Ciência Florestal) - Universidade Federal de Viçosa, Viçosa, 1994.

Avaliação quali-quantitativa da arborização e comparação econômica entre a poda e a substituição da rede de distribuição de energia elétrica da região administrativa de Belo Horizonte - MG. 2000. 219f. Tese (Doutorado em Ciência Florestal) - Universidade Federal de Viçosa, Viçosa, 2000.

SEITZ, R.A. Considerações sobre a poda de árvores na arborização urbana. In: ENCONTRO NACIONAL SOBRE ARBORIZAÇÃO URBANA, 3., 1990, Curitiba. Anais... Curitiba:.Fupef, 1990. p.87-100.

SILVAFILHO, D.F. da et al. Banco de dados relacional para cadastro, avaliação e manejo da arborização em vias públicas. Revista Árvore, Viçosa, v.26, n.5, p.629-642, 2002.

VELASCO, G.D.N. Arborização viária X sistema de distribuição de energia elétrica: avaliação dos custos, estudo das podas e levantamento de problemas fitotécnicos. 2003. 94f. Dissertação (Mestrado em Fitotecnia) - Escola Superior de Agricultura "Luiz de Queiroz", Universidade de São Paulo, Piracicaba, 2003. 
Tabela 1. Informações de três aspectos importantes: localização, infra-estrutura e dados sobre a árvore coletada para o início do trabalho (Tabela de campo)

Table 1. Table the field. The picture 1 shows the table used for data collection in public ways

\begin{tabular}{|c|c|c|c|c|c|c|c|c|c|c|c|c|c|c|c|}
\hline \multicolumn{3}{|c|}{ Bairro / District: } & \multicolumn{6}{|c|}{ Nome da rua / Name of street: } & \multicolumn{7}{|c|}{ Largura / Breadth } \\
\hline \multicolumn{3}{|c|}{$\begin{array}{l}\text { Largura calçada / } \\
\text { Breadth sidewalk: }\end{array}$} & \multicolumn{7}{|c|}{$\begin{array}{l}\text { Lado: A (presença de fiação) } \\
\text { Side: } A \text { (presence of spinning) }\end{array}$} & \multicolumn{4}{|c|}{$\begin{array}{l}\text { B (ausência de fiação) } \\
B \text { (absence of spinning) }\end{array}$} & & \\
\hline 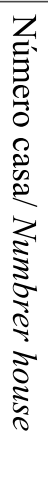 & 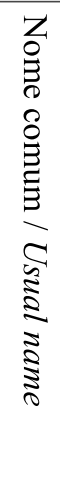 & 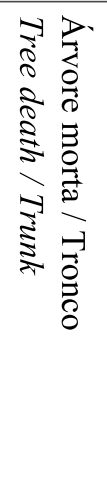 & 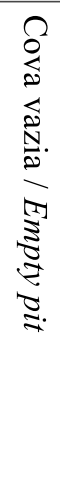 & 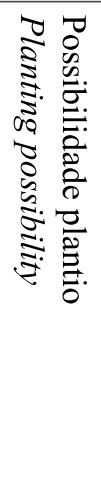 & $\begin{array}{l}\Omega \\
\underset{D}{D} \\
\underset{\sigma}{\sigma}\end{array}$ & 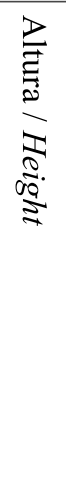 & 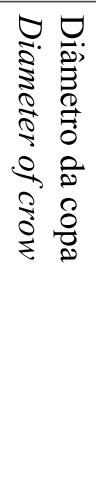 & 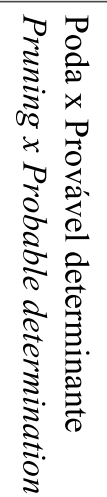 & 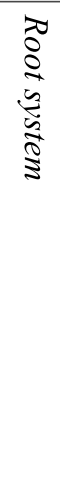 & 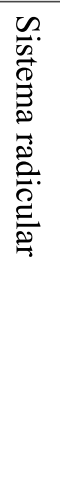 & 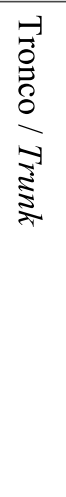 & $\begin{array}{l}7 \\
0 \\
0 \\
0 \\
0 \\
3 \\
2 \\
7 \\
0 \\
0 \\
0 \\
3\end{array}$ & 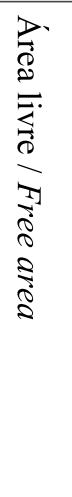 & $\begin{array}{l}0 . \\
\overrightarrow{0} \\
0 \\
0 \\
0 \\
\vdots \\
\vdots \\
0 \\
\vdots \\
\vdots\end{array}$ & 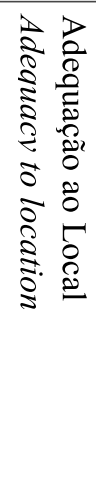 \\
\hline
\end{tabular}

Tabela 2. Distribuição quantitativa de cada espécie encontrada na arborização viária dos bairros Antônio Zanaga I e II de Americana/SP, com nome popular, nome científico, total de indivíduos, freqüência acima de $1 \%$ e origem (E exótica e $\mathrm{N}$ - nativa)

Table 2. Quantitative distribution of each species found in the urban forestry of Antonio Zanaga I and II districts of the municipality of Americana, SP, with common name, scientific name, total of individuals, frequency when higher than $1 \%$ and origin ( $E$ - exotics; $N$ - native)

\begin{tabular}{|c|c|c|c|c|}
\hline $\begin{array}{l}\text { Nome popular } \\
\text { Common name }\end{array}$ & $\begin{array}{l}\text { Nome científico } \\
\text { Scientific name }\end{array}$ & $\begin{array}{l}\text { Total } \\
\text { Total }\end{array}$ & $\begin{array}{c}\text { Freqüência \% } \\
\text { Frequency \% }\end{array}$ & $\begin{array}{c}\text { Origem } \\
\text { Origin }\end{array}$ \\
\hline Falsa-murta & Murraya paniculata (L.) Jacq. & 470 & 18,42 & $\mathrm{E}$ \\
\hline Ligustro & Ligustrum lucidum W. T. Aiton & 421 & 16,50 & $\mathrm{E}$ \\
\hline Oiti & Licania tomentosa (Benth.) Fritsch. & 318 & 12,47 & $\mathrm{~N}$ \\
\hline Canelinha & Nectandra megapotamica (Spreng.) Mez & 242 & 9,49 & $\mathrm{~N}$ \\
\hline Sibipiruna & Caesalpinia pluviosa DC. & 216 & 8,47 & $\mathrm{~N}$ \\
\hline Sete-copas & Terminalia catappa $\mathrm{L}$. & 192 & 7,53 & $\mathrm{E}$ \\
\hline Ficus-benjamim & Ficus benjamina $\mathrm{L}$. & 107 & 4,19 & $\mathrm{E}$ \\
\hline Aroeira-salsa & Schinus molle L. & 96 & 3,76 & $\mathrm{~N}$ \\
\hline Resedá-anão & Lagerstroemia indica $\mathrm{L}$. & 45 & 1,76 & $\mathrm{E}$ \\
\hline Mangueira & Mangifera indica $\mathrm{L}$. & 35 & 1,37 & $\mathrm{E}$ \\
\hline Ficus-variegata & Ficus benjamina L. var. variegata & 34 & 1,33 & $\mathrm{E}$ \\
\hline Ipê-mirim & Stenolobium stans (L.) Seem. & 34 & 1,33 & $\mathrm{E}$ \\
\hline Munguba & Pachira aquatica Aubl. & 28 & 1,10 & $\mathrm{~N}$ \\
\hline Outras / Other & & 313 & 12,30 & \\
\hline Total & & 2.551 & 100 & \\
\hline
\end{tabular}


Tabela 3. Porcentagem de espécies exóticas e nativas dos bairros analisados em Americana/SP

Table 3. Percentage of exotic and native species in the districts studied in Americana city, Brazil

\begin{tabular}{lcl}
\multicolumn{1}{c}{$\begin{array}{c}\text { Descrição das espécies } \\
\text { Description of species }\end{array}$} & $\begin{array}{c}\text { Quantidade de indivíduos } \\
\text { Quantity of individuals }\end{array}$ & $\begin{array}{c}\text { Porcentagem (\%) } \\
\text { Percentage (\%) }\end{array}$ \\
\hline Exóticas / Exotic & 1.495 & 58,60 \\
Nativas / Native & 1.056 & 41,40 \\
Total & 2.551 & 100 \\
\hline
\end{tabular}
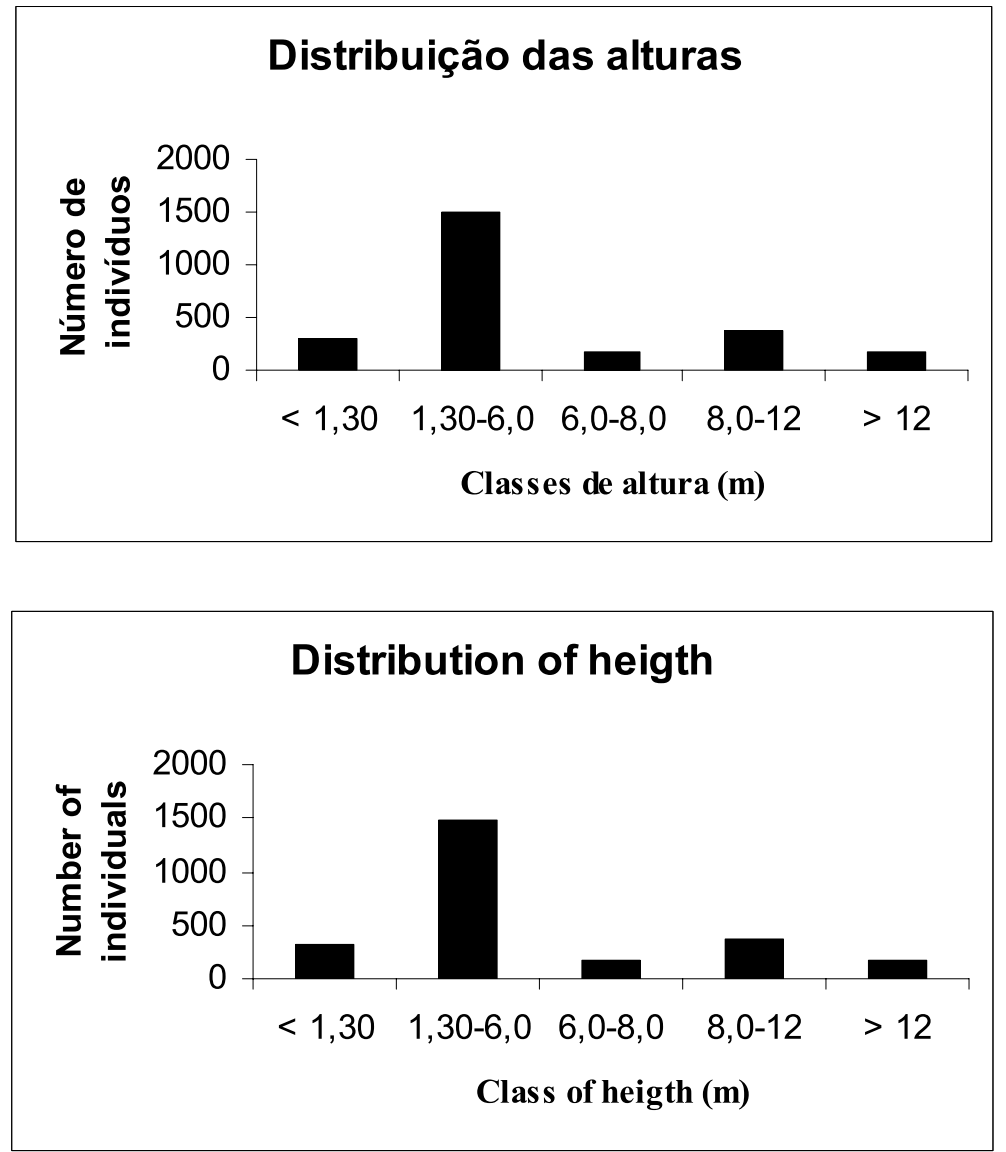

Figura 1. Alturas das árvores em dois bairros de Americana/SP.

Figure 1. Height of the trees in Americana districts. 
Tabela 4. Altura, quantidade (Qtd) e porcentagem (\%) de espécies em dois bairros de Americana/SP

Table 4. Height, quantity and percentage (\%) of species in Americana districts

\begin{tabular}{|c|c|c|c|c|c|c|c|c|c|c|c|}
\hline \multirow{2}{*}{$\begin{array}{l}\text { Espécies } \\
\text { Species }\end{array}$} & \multirow{2}{*}{$\begin{array}{l}\text { Nome científico } \\
\text { Scientific name }\end{array}$} & \multicolumn{2}{|c|}{$<1,30 \mathrm{~m}$} & \multicolumn{2}{|c|}{$\begin{array}{l}1,30 \mathrm{a} \\
6,00 \mathrm{~m}\end{array}$} & \multicolumn{2}{|c|}{$\begin{array}{l}6,00 \mathrm{a} \\
\mathbf{8 , 0 0} \mathrm{m}\end{array}$} & \multicolumn{2}{|c|}{$\begin{array}{c}8,00 \text { a } \\
12,00 \mathrm{~m}\end{array}$} & \multicolumn{2}{|c|}{$>12,00 \mathrm{~m}$} \\
\hline & & Qtd & $\%$ & Qtd & $\%$ & Qtd & $\%$ & Qtd & $\%$ & Qtd & $\%$ \\
\hline Falsa-murta & $\begin{array}{c}\text { Murraya } \\
\text { paniculata (L.) } \\
\text { Jacq }\end{array}$ & 96 & 30,77 & 367 & 24,58 & 1 & $0,57-$ & - & - & - & - \\
\hline Oiti & $\begin{array}{c}\text { Licania } \\
\text { tomentosa } \\
\text { (Benth.) Fritsch. }\end{array}$ & 65 & 20,83 & 232 & 15,54 & 10 & 5,71 & 7 & 1,93 & 1 & 0,55 \\
\hline Ipê-mirim & $\begin{array}{c}\text { Stenolobium } \\
\text { stans (L.) Seem. }\end{array}$ & 20 & 6,41 & 12 & 0,80 & - & - & - & - & - & - \\
\hline Aroeira-salsa & Schinus molle L. & 16 & 5,13 & 78 & 5,22 & 1 & 0,57 & - & - & 1 & 0,55 \\
\hline Ligustro & $\begin{array}{l}\text { Ligustrum } \\
\text { lucidum } \mathrm{W} . \mathrm{T} . \\
\text { Aiton }\end{array}$ & - & - & 241 & 16,14 & 43 & 24,57 & 99 & 27,27 & 31 & 17,13 \\
\hline $\begin{array}{l}\text { Ficus } \\
\text { bejamina }\end{array}$ & $\begin{array}{c}\text { Ficus benjamina } \\
\text { L. }\end{array}$ & - & - & 79 & 5,29 & 14 & 8,00 & 10 & 2,75 & 1 & 0,55 \\
\hline Sete-copas & $\begin{array}{l}\text { Terminalia } \\
\text { catappa } \mathrm{L}\end{array}$ & - & - & 64 & 4,29 & 33 & 18,85 & 63 & 17,36 & 30 & 16,57 \\
\hline Sibipiruna & $\begin{array}{c}\text { Caesalpinia } \\
\text { pluviosa DC. }\end{array}$ & - & - & 27 & 1,80 & 23 & 13,14 & 84 & 23,14 & 81 & 44,57 \\
\hline Canelinha & $\begin{array}{c}\text { Nectandra } \\
\text { megapotamica } \\
\text { (Spreng.) Mez }\end{array}$ & - & - & 152 & 10,18 & 26 & 14,86 & 38 & 10,47 & 15 & 8,29 \\
\hline Resedá-anão & $\begin{array}{l}\text { Lagerstroemia } \\
\text { indica } \mathrm{L} .\end{array}$ & - & - & 35 & 2,34 & - & - & - & - & - & - \\
\hline Outras/Other & & 115 & 36,86 & 206 & 13,18 & 24 & 13,71 & 71 & 19,61 & 21 & 11,60 \\
\hline Total & & 312 & 100 & 1.493 & 100 & 175 & 100 & 363 & 100 & 181 & 100 \\
\hline
\end{tabular}

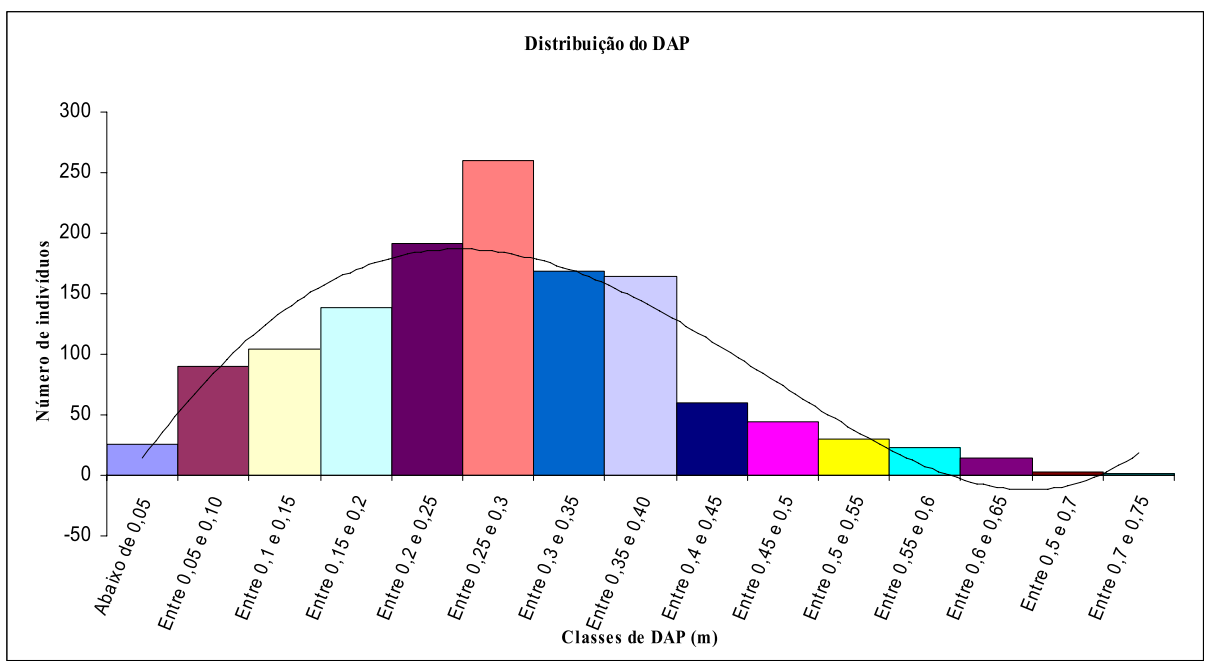

Figura 2. Número de indivíduos e distribuição do diâmetro à altura do peito (DAP) das árvores, em dois bairros da cidade de Americana/SP. 


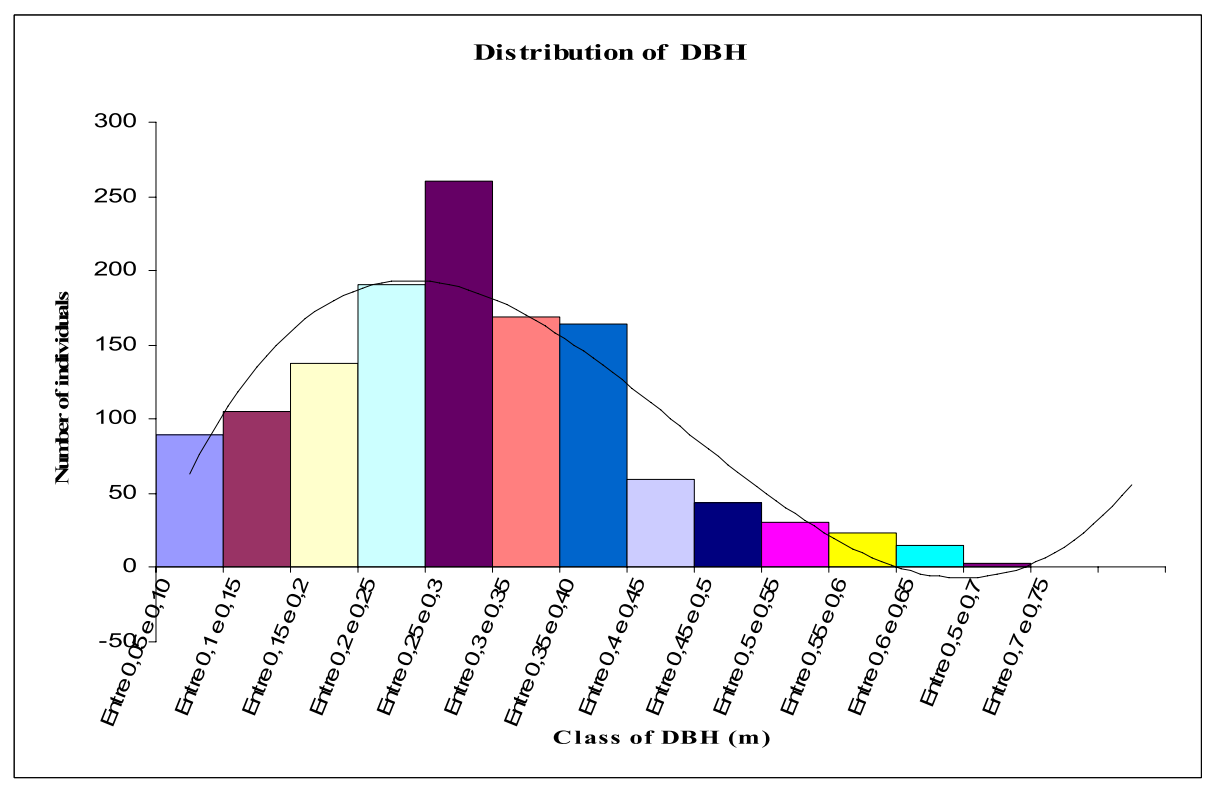

Figure 2. Number of individuals and distribution of tree diameter at chest height in Americana districts.

Tabela 5. Indivíduos que sofreram podas, seus tipos e os que não sofreram podas em dois bairros de Americana/SP Table 5. Individuals pruned, pruning types and non-pruned individuals Americana districts

\begin{tabular}{llcc}
\hline \multicolumn{1}{c}{$\begin{array}{c}\text { Descrição } \\
\text { Description }\end{array}$} & \multicolumn{1}{c}{$\begin{array}{c}\text { Tipos de podas } \\
\text { Type of pruning }\end{array}$} & $\begin{array}{c}\text { Quantidade de indivíduos } \\
\text { Quantity of individuals }\end{array}$ & $\begin{array}{c}\text { Porcentagem (\%) } \\
\text { Percentage (\%) }\end{array}$ \\
\hline $\begin{array}{l}\text { Sofreram podas } \\
\text { Pruned }\end{array}$ & Drástica / Drastic & 1.008 & 39,51 \\
& Topiaria / Topiary & 190 & 7,45 \\
& Forma de V / Form of $V$ & 81 & 3,17 \\
& Forma de L / Form of V & 63 & 2,47 \\
& Total & 1.342 & 52,60 \\
Não sofreram podas / Without pruning & 1.209 & 47,40 \\
Total & & 2.551 & 100 \\
\hline
\end{tabular}


Tabela 6. Motivos da necessidade de podas drásticas nos indivíduos de dois bairros de Americana/SP

Table 6. Motives of the necessity of drastic pruning in individuals in Americana districts

\begin{tabular}{lcc}
\multicolumn{1}{c}{\begin{tabular}{c}
\multicolumn{1}{c}{ Motivos } \\
Motives
\end{tabular}} & $\begin{array}{c}\text { Quantidade de indivíduos } \\
\text { Quantity of individuals }\end{array}$ & $\begin{array}{c}\text { Porcentagem (\%) } \\
\text { Percentage (\%) }\end{array}$ \\
\hline $\begin{array}{l}\text { Fiação elétrica } \\
\text { Electric spinning }\end{array}$ & 609 & 60,42 \\
$\begin{array}{l}\text { Falta de iluminação } \\
\text { Without ilumiation }\end{array}$ & 1 & 0,10 \\
$\begin{array}{l}\text { Entupimento de calhas } \\
\text { Choking of gutter }\end{array}$ & 35 & 3,47 \\
$\begin{array}{l}\text { Entrada de garagem } \\
\text { Entrance of garage }\end{array}$ & 5 & 0,50 \\
$\begin{array}{l}\text { Sem causa aparente } \\
\text { Without apparent cause }\end{array}$ & 358 & 31,52 \\
Total & 1.008 & 100 \\
\hline
\end{tabular}

Tabela 7. Espécies que apresentaram maiores porcentagens de podas, em dois bairros de Americana/SP Table 7. Species that showed the most pruning rate in Americana districts

\begin{tabular}{|c|c|c|c|c|c|c|c|c|c|c|c|}
\hline \multirow{2}{*}{$\begin{array}{l}\text { Espécies } \\
\text { Species }\end{array}$} & \multirow{2}{*}{$\begin{array}{c}\text { Nome } \\
\text { científico } \\
\text { Scientific } \\
\text { name }\end{array}$} & \multicolumn{2}{|c|}{$\begin{array}{l}\text { Condução } \\
\text { Condution }\end{array}$} & \multicolumn{2}{|c|}{$\begin{array}{l}\text { Topiaria } \\
\text { Topiary }\end{array}$} & \multicolumn{2}{|c|}{$\begin{array}{l}\text { Drástica } \\
\text { Drastic }\end{array}$} & \multicolumn{2}{|c|}{$\begin{array}{l}\text { Poda em V } \\
\text { Pruning in } V\end{array}$} & \multicolumn{2}{|c|}{$\begin{array}{l}\text { Poda em } \mathbf{L} \\
\text { Pruning in } L\end{array}$} \\
\hline & & Qtd & $\%$ & Qtd & $\%$ & Qtd & $\%$ & Qtd & $\%$ & Qtd & $\%$ \\
\hline Falsa-murta & $\begin{array}{c}\text { Murraya } \\
\text { paniculat } \\
a(\mathrm{~L} .) \\
\text { Jacq. }\end{array}$ & 266 & 31,74 & 80 & 42,10 & 22 & 2,18 & 2 & $2,50-$ & 5 & 7,93 \\
\hline Oiti & $\begin{array}{c}\text { Licania } \\
\text { tomentosa } \\
\text { (Benth.) } \\
\text { Fritsch. }\end{array}$ & 140 & 16,71 & 47 & 24,74 & 37 & 3,67 & 5 & 6,17 & 1 & 1,58 \\
\hline Ligustro & $\begin{array}{c}\text { Ligustrum } \\
\text { lucidum } \\
\text { W. T. } \\
\text { Aiton }\end{array}$ & 78 & 9,31 & 8 & 4,21 & 319 & 31,64 & 10 & 12,35 & 10 & 15,87 \\
\hline Ficus bejamina & $\begin{array}{c}\text { Ficus } \\
\text { benjamina } \\
\text { L. }\end{array}$ & 7 & 0,83 & 25 & 13,15 & 70 & 6,94 & - & - & 5 & 7,94 \\
\hline Canelinha & $\begin{array}{c}\text { Nectandra } \\
\text { megapota } \\
\text { mica } \\
\text { (Spreng.) } \\
\text { Mez }\end{array}$ & 35 & 4,17 & 12 & 6,31 & 175 & 17,75 & 3 & 3,70 & 11 & 17,46 \\
\hline Sete-copas & $\begin{array}{c}\text { Terminali } \\
\text { a catappa } \\
\mathrm{L} .\end{array}$ & 23 & 2,74 & - & - & 156 & 15,47 & 7 & 8,64 & 5 & 7,94 \\
\hline Sibipiruna & $\begin{array}{c}\text { Caesalpin } \\
\text { ia } \\
\text { pluviosa } \\
\text { DC. }\end{array}$ & 51 & 6,08 & 3 & 1,57 & 98 & 9,72 & 45 & 55,56 & 18 & 28,57 \\
\hline Outras/Other & & 238 & 28,40 & 15 & 7,89 & 131 & 13 & 9 & 11,11 & 8 & 12,70 \\
\hline Total & & 838 & 100 & 190 & 100 & 1008 & 100 & 81 & 100 & 63 & 100 \\
\hline
\end{tabular}


Tabela 8. Porcentagem de podas drásticas, motivadas pela fiação elétrica, em dois bairros de Americana/SP Table 8. Rate of drastic pruning caused by electric wires in Americana districts

\begin{tabular}{lccc}
\hline $\begin{array}{l}\text { Nome comum } \\
\text { Common name }\end{array}$ & $\begin{array}{c}\text { Nome científico } \\
\text { Scientific name }\end{array}$ & $\begin{array}{c}\text { Quantidade de indivíduos } \\
\text { Quantity of individuals }\end{array}$ & $\begin{array}{c}\text { Porcentagem (\%) } \\
\text { Percentage (\%) }\end{array}$ \\
\hline $\begin{array}{l}\text { Ligustro } \\
\text { Canelinha }\end{array}$ & $\begin{array}{c}\text { Ligustrum lucidum } \text { W. T. Aiton } \\
\text { Nectandra megapotamica } \text { (Spreng.) } \\
\text { Mez }\end{array}$ & 192 & 31,53 \\
Sete-copas & Terminalia catappa L. & 117 & 19,21 \\
Sibipiruna & Caesalpinia pluviosa DC. & 101 & 16,58 \\
Ficus benjamina & Ficus benjamina L. & 59 & 9,69 \\
Oiti & Licania tomentosa (Benth.) Fritsch. & 38 & 6,24 \\
Outras / Others & & 19 & 3,12 \\
\hline Total & & 63 & 13,63 \\
\hline
\end{tabular}

Tabela 9. Porcentagens de espécies com sistema radicular (S.R.) afetando a estrutura da calçada e com esse mesmo problema aliado a insuficiente área livre no canteiro, em dois bairros de Americana/SP

Table 9. Rate of species with their root system affecting the pavement structure, and presenting the same problem with insufficient free area in bed, in Americana districts

\begin{tabular}{|c|c|c|c|c|c|}
\hline $\begin{array}{l}\text { Espécies } \\
\text { Species }\end{array}$ & $\begin{array}{l}\text { Nome científico } \\
\text { Scientific name }\end{array}$ & $\begin{array}{l}\text { Quantidade de } \\
\text { indivíduos } \\
\text { Quantity of } \\
\text { individuals }\end{array}$ & $\begin{array}{c}\text { S.R. } \\
\text { afetando } \\
(\%) \\
\text { Root system } \\
\text { affecting (\%) }\end{array}$ & $\begin{array}{l}\text { Quantidade } \\
\quad \text { de } \\
\text { indivíduos } \\
\text { Quantity of } \\
\text { individuals }\end{array}$ & $\begin{array}{l}\text { S.R. afetando e } \\
\text { área livre } \\
\text { insuficiente (\%) } \\
\text { Root system } \\
\text { affecting and } \\
\text { insufficient free } \\
\text { area (\%) }\end{array}$ \\
\hline Ligustro & $\begin{array}{l}\text { Ligustrum lucidum W. } \\
\text { T. Aiton }\end{array}$ & 245 & 28,00 & 99 & 27,35 \\
\hline Sibipiruna & $\begin{array}{l}\text { Caesalpinia pluviosa } \\
\text { DC. }\end{array}$ & 178 & 20,34 & 84 & 23,20 \\
\hline Sete-copas & Terminalia catappa $\mathrm{L}$. & 126 & 14,40 & 62 & 17,13 \\
\hline Canelinha & $\begin{array}{l}\text { Nectandra } \\
\text { megapotamica (Spreng.) } \\
\text { Mez }\end{array}$ & 115 & 13,14 & 38 & 10,50 \\
\hline $\begin{array}{l}\text { Outras / } \\
\text { Others }\end{array}$ & & 211 & 24,11 & 79 & 21,82 \\
\hline Total & & 875 & 100 & 362 & 100 \\
\hline
\end{tabular}


Tabela 10. Porcentagem das condições de tronco nas árvores de dois bairros de Americana/SP

Table 10. Rate of trunk conditions in the trees of Americana districts

\begin{tabular}{lcc}
\multicolumn{1}{c}{$\begin{array}{c}\text { Tronco } \\
\text { Trunk }\end{array}$} & $\begin{array}{c}\text { Quantidade de indivíduos } \\
\text { Quantity of individuals }\end{array}$ & $\begin{array}{c}\text { Porcentagem (\%) } \\
\text { Percentage (\%) }\end{array}$ \\
\hline $\begin{array}{l}\text { Fendas longitudinais } \\
\text { Longitudinal fissure } \\
\text { Sem injúrias } \\
\text { Without injury }\end{array}$ & 2122 & 86,58 \\
$\begin{array}{l}\text { Oco, com cavidades } \\
\text { Hole }\end{array}$ & 142 & 5,79 \\
$\begin{array}{l}\text { Anelamento } \\
\text { Annular }\end{array}$ & 127 & 5,18 \\
Inclinado & & 0,41 \\
Inclined & 10 & 2,04 \\
Total & 50 & 100 \\
\hline
\end{tabular}

Tabela 11. Porcentagem de indivíduos que apresentaram problemas e adequação ao local em dois bairros de Americana/SP Table 11. Rate of individuals showing problems and adequacy to location in Americana districts

\begin{tabular}{cccccc}
\hline $\begin{array}{c}\text { Problemas } \\
\text { Problems }\end{array}$ & $\begin{array}{c}\text { Quantidade de } \\
\text { indivíduos } \\
\text { Quantity of } \\
\text { individuals }\end{array}$ & $\begin{array}{c}\text { Porcentagem } \\
\mathbf{( \% )}\end{array}$ & $\begin{array}{c}\text { Adequação } \\
\text { Po local } \\
\text { Pdequacy to } \\
\text { location }\end{array}$ & $\begin{array}{c}\text { Quantidade } \\
\text { de indivíduos } \\
\text { Quantity of } \\
\text { individuals }\end{array}$ & $\begin{array}{c}\text { Porcentagem } \\
\text { (\%) }\end{array}$ \\
\hline $\begin{array}{c}\text { Percentage } \\
\text { Praga }\end{array}$ & 304 & 11,92 & $\begin{array}{c}\text { Adequada } \\
\text { Adequate }\end{array}$ & 925 & 36,26 \\
$\begin{array}{c}\text { Poença } \\
\text { Disease }\end{array}$ & 233 & 9,13 & $\begin{array}{c}\text { Inadequada } \\
\text { Inadequate }\end{array}$ & 1626 & 63,74 \\
Outras / Others & 2.014 & 78,94 & Total & 2.551 & 100 \\
Total & 2.551 & 100 & & \\
\hline
\end{tabular}

